Monthly GDP Estimates for Inter-War Britain

James Mitchell, Solomos Solomou and Martin Weale

September 2011

CWPE 1155 


\title{
MONTHLY GDP ESTIMATES FOR INTER-WAR BRITAIN
}

\author{
James Mitchell \\ National Institute of Economic and Social Research \\ Solomos Solomou \\ Faculty of Economics, \\ University of Cambridge \\ Martin Weale \\ National Institute of Economic and Social Research \\ and Monetary Policy Committee, Bank of England
}

\section{1}

\begin{abstract}
We derive monthly and quarterly series of UK GDP for the inter-war period from a set of monthly indicators that were constructed by The Economist at the time. The monthly information is complemented with data for quarterly industrial production, allowing us to employ mixed-frequency methods to produce monthly estimates of GDP and of industrial production. We proceed to illustrate how the new data compare with existing high frequency data and how they can be used to contribute to our understanding of the economic history of the UK in the inter-war period and to draw comparisons between recession profiles in the inter-war and the post-war period.
\end{abstract}

Key Words: Economic History, National Accounts, Monthly GDP Data, Great Depression

JEL Reference: N34, C82 
Gross domestic product is generally regarded as the most appropriate indicator of economic activity. But for the inter-war period the data are only available at the annual frequency. As such, many important questions cannot be addressed in a satisfactory manner. If we are interested in the impact of historical events, such as the effect of policy changes that take place at discrete points in time, we are limited to using either annual data ${ }^{1}$ or indicators of economic activity at a monthly or quarterly frequency that may not fully capture macroeconomic movements. But to understand the economic impact of many important events it is necessary to have data available at a higher frequency that are reliable and consistent with the annual national accounts. In this article we describe a monthly series of GDP and a monthly series of industrial production for the United Kingdom for the period 1920-1938 and we show that it, used in conjunction with other monthly indicators, clarifies our understanding of some of the major economic events of the period. The index can also be aggregated to the quarterly frequency, allowing researchers to discuss the inter-war economy more effectively using data at the quarterly frequency.

A considerable amount of work has been done on the development of monthly indicators of economic activity. Perhaps the best known is provided by the system of indicators developed by Burns and Mitchell (1946). Their work was anticipated by The Economist, which collected monthly indicators during the period 1920-1938 and published an aggregate indicator of "Business Activity", computed as the geometric mean of the indicators they collected ${ }^{2}$. The data set from The Economist forms the basis of the monthly GDP indicator that we present here, together with data for quarterly industrial production ${ }^{3}$. Averaging the indicator variables is not the only possible method of aggregation. Rhodes (1937) suggested instead that the first

\footnotetext{
${ }^{1}$ The first set of consistent historical national accounts was provided by Feinstein (1972). Improvements to the inter-war national accounts were made more recently by Sefton and Weale (1995) and Solomou and Weale (1993) who allocated the discrepancies between income and expenditure in Feinstein's estimates so as to produce balanced national accounts for the period since 1920.

${ }^{2}$ The monthly indicators and the component series were published regularly in The Economist 'Trade Supplement'. The series was extended back to the period 1920-23 by the Economist, but the compilers recognised that the data were "much less reliable for the years before 1924" (Capie and Collins, 1983, p. 45).

${ }^{3}$ For the period 1924-38 the indices covered coal consumption, electricity consumption, merchandise on railways, commercial motors in use, postal receipts, building activity, iron and steel for home consumption, raw cotton delivered to mills, imports of raw materials, exports British manufactures, shipping movements, bank clearings (metropolitan) and bank clearings (towns). For the period 1920-23 a more limited set of indicators were collected including coal consumption, iron and steel consumption, cotton consumption, merchandise carried on railways and exports.
} 
principal component of the series could be used. This amounts to identifying an aggregate which, on its own, accounts for as much as possible of the overall variation in the data set. Much more recently Stock and Watson (2002), while unaware of Rhodes work, have used the same approach to derive a monthly indicator of the US economy. While the first principal component may be a good summary of the data, it is not necessarily the aggregate that is most closely correlated with GDP. Some means is needed of selecting from the indicators a composite which is closely linked to GDP rather than one which is simply a summary of the indicator data set. In this paper we derive monthly GDP series using the latent indicator methodology outlined below. We present the new data set and compare the high-frequency description of the British economy with other studies. As a way of highlighting some interesting features of the new data we consider three examples: first, we discuss how high frequency data improve our understanding of the 1920-1 depression; secondly we consider the role of policy in ending the Great Depression in the British economy; finally, we use the data to compare the high frequency time-profile of the depression of the 1930s with more recent recessions. ${ }^{4}$ Our hope is that the availability of this data will encourage more research into the high frequency aspects of the British inter-war economy and to widen the possibilities of comparative analysis using high-frequency data.

\section{Statistical Methodology}

The econometric methodology used to construct our indicator of monthly GDP from the available annual GDP data, the quarterly industrial production data and the monthly indicator variables is outlined below. When there are only a few clearly relevant monthly indicator variables available, regression can be used to construct the monthly GDP estimates. Mitchell et al. (2005) discuss the use of mixed-frequency variables (such as a combination of monthly and quarterly or annual variables) in

\footnotetext{
${ }^{4}$ Our focus in this work is on periods of economic weakness; we compare the 1930s with more recent experience. In our discussion we use the term recession to mean a period when output is falling (i.e. the economy is receding) and depression to mean a period when output is below some reference value such as the peak reached before a recession started. Thus the terms do not convey anything about the severity of the different episodes. A depression lasts longer than a recession simply because once output starts rising after a recession it inevitably takes some time to surpass its previous peak. Our emphasis, then, is on depressions thus defined.
} 
regression equations and go on to show how such equations can be used to produce monthly estimates of GDP. But the fact that we have a reasonably large number of monthly indicator variables from The Economist makes it difficult to use their methods satisfactorily since the regression would run into degree-of-freedom constraints. An alternative methodology is to assume that the indicators, industrial production and GDP are driven, at the monthly frequency, by an underlying unobserved or latent variable. Estimates of this unobserved variable can then be used to provide a monthly indicator of GDP and the resulting monthly estimates can be adjusted, so that the monthly totals sum to the estimates of annual GDP, making the monthly estimates consistent with the annual national accounts. On a technical level, an additional advantage of the method we employ is that it provides an exact solution to the problem that when modelling the logarithm of GDP, as is preferable to modelling the level of GDP, the sum of the interpolated monthly values nevertheless equals the known annual total.

In the absence of monthly economic data, which while not measures of GDP itself are believed to provide some clue about monthly movements in GDP, the best that can be done is to interpolate the annual GDP data using a univariate (dynamic) model. This is clearly not ideal, as important but offsetting intra-year movements in GDP will be missed, since the statistical model assumed to govern the determination of monthly GDP can at best be fitted to the available annual GDP data.

Fortunately, as discussed above, a range of relevant monthly indicator series, drawn from The Economist and used by Rhodes (1937), is available for the UK over the 1920-1938 period. Together with the quarterly industrial production series (Capie and Collins, 1983) these data provide an indication of monthly/quarterly movements in economic activity. However, they do not measure GDP itself and at best can be viewed as providing an incomplete picture. For these monthly/quarterly data to be used to draw inferences about the state of the economy as a whole it is desirable that there should be some formal statistical procedure for exploiting them and arriving at an indicator of monthly GDP. Such a procedure is likely to produce estimates of GDP which are less satisfactory than those which might have been produced by direct measurement but is preferable simply to "eye-balling” or averaging the indicator series and drawing subjective conclusions about the likely behaviour of monthly GDP in the absence of any statistical knowledge of how these series might relate to GDP. As Rhodes (1937, p. 18) notes it is necessary to "reduce this mass of data... to a more 
digestible form”. Somewhat differently from Rhodes' own objective (which has also been shared by a recent econometric literature spurred by Stock and Watson, 1991) we seek to reduce the monthly/quarterly data to an estimator of monthly GDP itself. Importantly, in contrast to this literature, this means we also consider annual GDP data and therefore adopt a mixed-frequency approach to deriving monthly estimates of GDP.

Following Stone (1947) and Stock and Watson (1991) our dynamic factorbased methodology assumes that a latent variable or "factor", taken to represent the "business cycle", drives variations and co-movements in the observed monthly, quarterly and annual data. Importantly, this assumption is consistent with Burns and Mitchell's (1946) characterisation of the "business cycle” as common movements in different economic indicators. Booms and recessions are marked, respectively, not just by one but by a range of economic indicators rising and falling.

A (dynamic) factor-based approach provides a parsimonious means of characterising fluctuations in a reasonably large number of variables. In this approach each of the observed variables (the monthly indicators, industrial production and GDP itself) is then assumed to deviate from this common factor by an idiosyncratic component, specific to each series. These idiosyncratic components are allowed to follow distinct dynamic processes. This flexibility means that the model provides a good fit to the data.

The "business cycle" is also allowed to have a differential effect on the different variables. It is found, for example, that all of the monthly indicator variables in The Economist, as well as industrial production and GDP, are "coincident indicators", in the sense that they rise and fall with the "business cycle". But the "business cycle” has a particularly strong effect, as we might expect, on GDP itself; although it is again important to allow for idiosyncratic dynamics to capture the noise evident in monthly GDP movements. In other words, while the "business cycle" captures the general tendency for GDP to rise and fall, it remains important, in order to achieve a good fit of the data, to model also the higher-frequency noise specific to monthly GDP movements.

The particular model employed is based on Proietti and Moauro (2006). Their model has the attraction of letting us work in the log-levels of the variables, rather than their growth rates as in Stock and Watson (1991) and can handle mixed frequency data. 
Consider the $\mathrm{N}$-vector of monthly time-series $\mathbf{y}_{t, m}$, where the subscript $t$ denotes the particular year, $q$ the quarter within that year and $m$ the month within that year, $m=1, \ldots, 12 ; q=1,2,3,4$ and $t=1, \ldots, T$. It is assumed that $\mathbf{y}_{t, m}$, perhaps after a logarithmic transformation, is a linear combination of a (scalar) common factor $\mu_{t, m}$, which represents the "business cycle", and an idiosyncratic N-vector component $\boldsymbol{\mu}_{t, m}^{*}$. The business cycle's effect on each of the $\mathrm{N}$ time-series in $\mathbf{y}_{t, m}$ can differ and is determined by the $\mathrm{N}$-vector of factor loadings, $\boldsymbol{\theta}$. The model can be represented as:

$$
\left.\begin{array}{l}
\mathbf{y}_{t, m}=\boldsymbol{\theta} \mu_{t, m}+\boldsymbol{\mu}_{t, m}^{*}, t=1, \ldots, T ; m=1, \ldots, 12 \\
\phi(L) \Delta \mu_{t, m}=\eta_{t, m}, \eta_{t, m} \sim \operatorname{NID}\left(0, \sigma_{\eta}^{2}\right) \\
\mathbf{D}(L) \Delta \boldsymbol{\mu}_{t, m}^{*}=\boldsymbol{\beta}+\boldsymbol{\eta}_{t, m}^{*}, \boldsymbol{\eta}_{t, m}^{*} \sim \operatorname{NID}\left(\mathbf{0}, \boldsymbol{\Sigma}_{\boldsymbol{\eta}^{*}}\right)
\end{array}\right\}
$$

where $\phi(L)=1-\phi_{1} L-\ldots-\phi_{p} L^{p}$ is an autoregressive polynomial of order $p$ with stationary roots and the matrix polynomial $\mathbf{D}(L)$ is diagonal with elements equal to $d_{i}(L)=1-d_{i 1} L-\ldots-d_{i p_{i}} L^{p_{i}}, \boldsymbol{\Sigma}_{\boldsymbol{\eta}^{*}}=\operatorname{diag}\left(\sigma_{1}^{2}, \ldots, \sigma_{N}^{2}\right)$ and the disturbances $\eta_{t, m}$ and $\boldsymbol{\eta}_{t, m}^{*}$ are independently distributed.

Model (1) implies that each individual time-series $\Delta y_{i t, m}(i=1, \ldots, N)$, expressed as a first difference, is composed of a mean (drift) term $\beta_{i}$, an individual autoregressive (AR) process $d_{i}(L)^{-1} \eta_{i t, m}^{*}$ as well as the business cycle (common) AR component $\phi(L)^{-1} \eta_{t, m}$. Following Stock and Watson (1991), we identify the parameters by setting $\sigma_{\eta}^{2}=1$ and assuming a zero drift in the equation for $\Delta \mu_{t, m}$. Model (1) is flexible. It can accommodate elements of $\mathbf{y}_{t, m}$ being I(1); both the common trend $\mu_{t, m}$ and the idiosyncratic components $\boldsymbol{\mu}_{t, m}^{*}$ are modelled as difference stationary processes. Proietti and Moauro (2006) explain how this model can be cast in statespace form, which is the precursor to estimation of the model by maximum likelihood using the Kalman filter. 
However, while the model (1) governing the determination of $\mathbf{y}_{t, m}$ is considered at the monthly frequency, actual observations for some of the $\mathrm{N}$ variables might not be available each month. In particular, we partition $\mathbf{y}_{t, m}$ into $\mathbf{y}_{t, m}=\left(\mathbf{y}_{1 t, m}^{\prime}, y_{2 t, m}, y_{3 t, m}\right)^{\prime}$ where $\mathbf{y}_{1 t, m}$ represents the observed monthly indicators from The Economist (considered further below) and $y_{2 t, m}$ and $y_{3 t, m}$ represent monthly industrial production and GDP, respectively, which, of course, are latent and the variables we wish to estimate.

Fortunately, we do observe annual GDP data $y_{3 t}$, such that

$y_{3 t}=\sum_{m=1}^{12} y_{3 t, m}$

Similarly, we observe quarterly industrial production data $y_{2 q}$, such that

$y_{2 q}=\sum_{m=(q-1) * 3+1}^{m=q^{*}} y_{2 t, m} ; q=1, \ldots, 4$.

Harvey and Pierse (1984) first explained how a model like (1), when cast in statespace form, can be estimated subject to (flow) aggregation constraints like (2) and (3) and knowledge only of the annual GDP data, $y_{3 t}$, and/or the quarterly industrial production data, $y_{2 q}$. This is achieved by augmenting the state-space representation of model (1) with a so-called cumulator variable that ensures (2) or (3) is satisfied. The Kalman smoother is then used to compute the minimum mean squared error estimates for the missing observations $y_{2 t, m}$ and $y_{3 t, m}$.

As Mitchell et al. (2005) explain the state-space approach to interpolation can be seen as asymptotically equivalent to regression-based methods. The latter were first developed by Chow and Lin (1971), and generalised to a dynamic non-stationary setting by Mitchell et al. (2005). These methods first aggregate the latent monthly model, which relates monthly GDP to the observed monthly indicators, so as to obtain an estimable equation in the observed annual data. Estimates of the unobserved 
monthly interpolands may then be produced by means of the latent monthly regression equation, and estimated coefficients based on the annual model, using data on the observable monthly indicators.

When $\mathbf{y}_{t, m}$ represents the logarithms of the original time-series the temporal aggregation constraint, seen previously in (2) and (3), is nonlinear: the sum of the logarithms is not the logarithm of the sum. We follow Proietti and Moauro (2006) and use their iterative algorithm to ensure the nonlinear aggregation constraint is met exactly given we model the data considered below in logarithms.

Estimation subject to the two aggregation constraints, (2) and (3), is facilitated by adopting a recursive structure whereby industrial production, as a component of GDP, affects GDP, but GDP does not affect industrial production. This means we first estimate $y_{2 t, m}$ as a function of $\mathbf{y}_{1 t, m}$ subject to (3), and obtain consistent estimates $\hat{y}_{2 t, m}$, and then estimate $y_{3 t, m}$ as a function of $\mathbf{y}_{1 t, m}$ and $\hat{y}_{2 t, m}$, subject to (2).

\section{1 Monthly and Quarterly GDP Series}

For completeness we present data at both market prices and factor cost, but focus our attention on the market price data. In the Appendix we provide details of the data and the parameter estimates used when estimating market price data.

Table 1 and Figure 1 present the new monthly GDP series in 1938 prices for the inter-war period. The main contribution of the new data is in the macroeconomic description of the high-frequency path of the economy. A number of important features stand out: first, the turning points of the 1920-1 depression differ from the NBER dating. Burns and Mitchell (1946) dated the UK depression as starting in March 1920 and reaching a trough in June 1921. In our monthly GDP series the starting point of the depression is August 1920 and the trough is in May 1921. Secondly, the return to gold in 1925 is correlated with a downturn in the months of April-July 1925. Thirdly, the weakness of the economy in 1928, highlighted in Solomou and Weale (1996), stands out in the high frequency data but is limited to the months of March-June. 
Conventionally, the peak of the UK economy in 1929 is dated as July 1929 and the third quarter of 1929 (Burns and Mitchell, 1946). The new data show the peak as being January 1930 (with another local peak in October 1929). The dating of the recovery is also different from that reported in Burns and Mitchell (1946). On a monthly basis they date the trough as August 1932 and, on a quarterly basis, as third quarter 1932. Our data also suggests that the trough is best dated as September 1932, although the economy continued to display some weakness in the early months of 1933. The turning points of the 1937-8 recession are also different from those outlined in Burns and Mitchell who date the peak as September 1937. The new data suggest that GDP moved into recession in December 1937 (using market prices). Such differences may seem minor in that the order of magnitude is a few months but they can have substantial implications for particular questions. For example, if we wish to address the role of particular policies in generating recovery from the Great Depression, a few months can have implications for the analysis of the transmission mechanism by which policies may have had an impact. However, the main advantage of the new data is that it provides a time profile of the path of the economy throughout the interwar period.

The new data can also be aggregated to generate quarterly estimates of GDP. The quarterly data are presented in Table 2 and Figure 2. To help the reader evaluate our data series we also compare both our series with the quarterly estimates of interwar GDP at factor cost reported in Hayes and Turner (2007). All three sets of data are presented as indices with the average for 1920-1938 set to 100 . 
Figure 1: Monthly GDP at 1938 Market Prices and Factor Cost

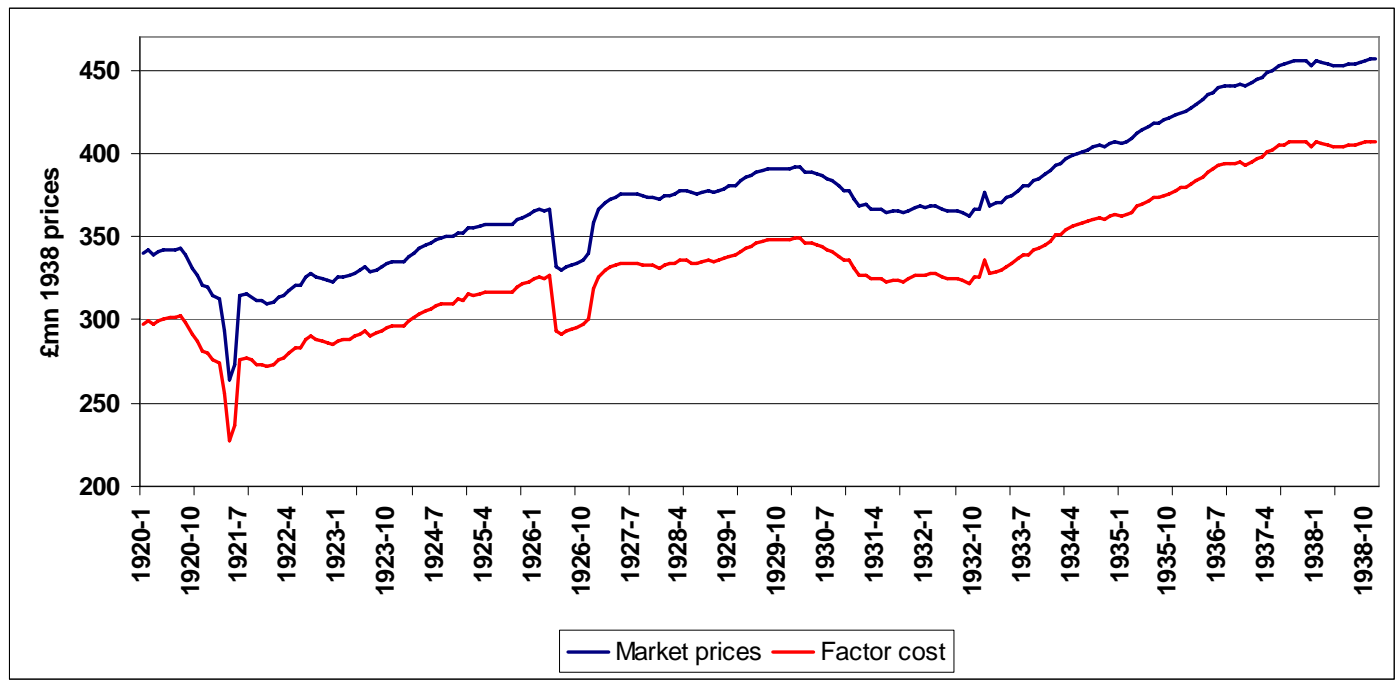


Table 1a: 1920-38 Monthly GDP at Market Prices, £mn 1938 prices

\begin{tabular}{llllllllllllll}
\hline & & & & & & & & & & & & & \\
& Jan & Feb & Mar & Apr & May & Jun & Jul & Aug & Sep & Oct & Nov & Dec \\
$\mathbf{1 9 2 0}$ & 339.71 & 341.67 & 338.77 & 340.80 & 341.66 & 341.99 & 342.44 & 342.90 & 338.67 & 331.40 & 326.54 & 320.44 \\
$\mathbf{1 9 2 1}$ & 319.27 & 314.83 & 312.61 & 293.29 & 264.14 & 273.25 & 314.97 & 315.56 & 313.81 & 311.28 & 311.35 & 309.64 \\
$\mathbf{1 9 2 2}$ & 310.53 & 313.25 & 314.55 & 317.89 & 320.57 & 321.02 & 325.97 & 328.21 & 325.40 & 324.68 & 323.42 & 322.51 \\
$\mathbf{1 9 2 3}$ & 325.54 & 325.88 & 326.69 & 327.99 & 329.51 & 331.63 & 328.85 & 330.32 & 332.01 & 334.07 & 334.51 & 334.99 \\
$\mathbf{1 9 2 4}$ & 335.11 & 337.66 & 339.82 & 342.63 & 345.16 & 346.47 & 348.16 & 349.39 & 349.84 & 349.96 & 352.56 & 352.24 \\
$\mathbf{1 9 2 5}$ & 355.54 & 355.02 & 356.13 & 357.04 & 357.04 & 357.21 & 357.17 & 357.01 & 357.54 & 360.29 & 361.85 & 363.14 \\
$\mathbf{1 9 2 6}$ & 365.27 & 366.10 & 365.48 & 366.92 & 332.01 & 330.21 & 332.27 & 333.33 & 333.97 & 336.49 & 340.26 & 358.70 \\
$\mathbf{1 9 2 7}$ & 366.54 & 370.99 & 372.55 & 374.00 & 375.39 & 375.17 & 375.65 & 375.39 & 374.74 & 373.95 & 373.89 & 372.75 \\
$\mathbf{1 9 2 8}$ & 374.51 & 375.04 & 376.02 & 378.04 & 377.60 & 376.12 & 375.91 & 376.64 & 377.43 & 377.05 & 377.57 & 379.08 \\
$\mathbf{1 9 2 9}$ & 380.42 & 380.80 & 383.75 & 385.55 & 386.72 & 388.57 & 389.97 & 390.87 & 390.80 & 390.59 & 391.27 & 390.68 \\
$\mathbf{1 9 3 0}$ & 392.25 & 391.45 & 389.14 & 388.90 & 387.30 & 386.49 & 384.37 & 383.60 & 380.60 & 378.01 & 377.86 & 373.03 \\
$\mathbf{1 9 3 1}$ & 368.65 & 369.11 & 366.90 & 366.61 & 366.69 & 364.78 & 365.06 & 365.09 & 363.99 & 365.94 & 367.96 & 368.23 \\
$\mathbf{1 9 3 2}$ & 367.40 & 368.29 & 368.46 & 366.34 & 365.14 & 365.47 & 365.25 & 364.05 & 362.29 & 366.27 & 366.62 & 376.43 \\
$\mathbf{1 9 3 3}$ & 368.53 & 370.05 & 370.35 & 373.25 & 374.92 & 378.10 & 380.35 & 381.14 & 383.42 & 385.01 & 387.49 & 389.39 \\
$\mathbf{1 9 3 4}$ & 393.11 & 394.11 & 396.87 & 399.13 & 400.23 & 401.22 & 402.42 & 403.96 & 404.58 & 404.37 & 406.25 & 406.76 \\
$\mathbf{1 9 3 5}$ & 406.38 & 407.09 & 408.84 & 412.61 & 414.40 & 416.03 & 417.99 & 418.43 & 419.94 & 421.05 & 423.40 & 424.83 \\
$\mathbf{1 9 3 6}$ & 425.27 & 427.69 & 429.62 & 432.15 & 435.04 & 436.68 & 439.55 & 440.65 & 440.34 & 440.31 & 441.50 & 440.20 \\
$\mathbf{1 9 3 7}$ & 442.43 & 444.59 & 445.18 & 448.49 & 450.17 & 453.09 & 453.54 & 455.07 & 455.59 & 455.38 & 455.70 & 452.78 \\
$\mathbf{1 9 3 8}$ & 455.70 & 454.87 & 453.49 & 452.97 & 453.23 & 452.30 & 453.44 & 453.54 & 454.88 & 456.15 & 456.43 & 457.00 \\
\hline \hline
\end{tabular}

Table 1b: 1920-1938 Monthly GDP Data at Factor Cost, £mn 1938 prices

\begin{tabular}{lllllllllllll}
\hline \hline & & & & & & & & & & & & \\
& Jan & Feb & Mar & Apr & May & Jun & Jul & Aug & Sep & Oct & Nov & Dec \\
$\mathbf{1 9 2 0}$ & 297.78 & 299.92 & 297.36 & 299.53 & 300.58 & 301.11 & 301.74 & 302.41 & 298.51 & 291.67 & 287.11 & 281.28 \\
$\mathbf{1 9 2 1}$ & 280.15 & 275.91 & 273.87 & 255.43 & 227.85 & 236.55 & 276.54 & 277.20 & 275.63 & 273.32 & 273.52 & 272.04 \\
$\mathbf{1 9 2 2}$ & 273.10 & 275.88 & 277.22 & 280.50 & 283.12 & 283.56 & 288.36 & 290.55 & 287.82 & 287.12 & 285.87 & 284.92 \\
$\mathbf{1 9 2 3}$ & 287.74 & 287.99 & 288.73 & 289.96 & 291.41 & 293.44 & 290.72 & 292.12 & 293.72 & 295.65 & 296.04 & 296.47 \\
$\mathbf{1 9 2 4}$ & 296.58 & 299.00 & 301.00 & 303.61 & 305.94 & 307.07 & 308.58 & 309.66 & 309.98 & 310.01 & 312.46 & 312.11 \\
$\mathbf{1 9 2 5}$ & 315.29 & 314.76 & 315.81 & 316.66 & 316.65 & 316.82 & 316.80 & 316.67 & 317.23 & 319.95 & 321.52 & 322.85 \\
$\mathbf{1 9 2 6}$ & 324.99 & 325.88 & 325.35 & 326.79 & 292.94 & 291.24 & 293.30 & 294.37 & 294.99 & 297.40 & 300.99 & 318.77 \\
$\mathbf{1 9 2 7}$ & 326.19 & 330.35 & 331.73 & 333.04 & 334.32 & 334.02 & 334.43 & 334.11 & 333.41 & 332.58 & 332.48 & 331.34 \\
$\mathbf{1 9 2 8}$ & 333.05 & 333.55 & 334.47 & 336.39 & 335.92 & 334.45 & 334.23 & 334.94 & 335.70 & 335.30 & 335.78 & 337.21 \\
$\mathbf{1 9 2 9}$ & 338.46 & 338.77 & 341.59 & 343.27 & 344.35 & 346.08 & 347.36 & 348.16 & 348.01 & 347.74 & 348.38 & 347.84 \\
$\mathbf{1 9 3 0}$ & 349.47 & 348.74 & 346.48 & 346.23 & 344.68 & 343.90 & 341.86 & 341.15 & 338.26 & 335.75 & 335.60 & 330.85 \\
$\mathbf{1 9 3 1}$ & 326.49 & 326.91 & 324.81 & 324.62 & 324.80 & 323.06 & 323.44 & 323.58 & 322.65 & 324.67 & 326.78 & 327.20 \\
$\mathbf{1 9 3 2}$ & 326.58 & 327.59 & 327.84 & 325.84 & 324.72 & 325.07 & 324.88 & 323.72 & 322.01 & 325.87 & 326.20 & 335.69 \\
$\mathbf{1 9 3 3}$ & 327.88 & 329.24 & 329.45 & 332.19 & 333.74 & 336.75 & 338.86 & 339.54 & 341.65 & 343.09 & 345.42 & 347.20 \\
$\mathbf{1 9 3 4}$ & 350.79 & 351.68 & 354.27 & 356.36 & 357.31 & 358.17 & 359.24 & 360.65 & 361.16 & 360.85 & 362.57 & 362.95 \\
$\mathbf{1 9 3 5}$ & 362.43 & 362.99 & 364.59 & 368.16 & 369.82 & 371.32 & 373.15 & 373.49 & 374.85 & 375.83 & 378.03 & 379.35 \\
$\mathbf{1 9 3 6}$ & 379.73 & 382.02 & 383.81 & 386.17 & 388.87 & 390.38 & 393.09 & 394.07 & 393.66 & 393.52 & 394.55 & 393.13 \\
$\mathbf{1 9 3 7}$ & 395.12 & 397.08 & 397.52 & 400.60 & 402.16 & 404.92 & 405.31 & 406.74 & 407.19 & 406.91 & 407.16 & 404.29 \\
$\mathbf{1 9 3 8}$ & 407.14 & 406.31 & 404.91 & 404.34 & 404.52 & 403.53 & 404.56 & 404.57 & 405.76 & 406.87 & 407.02 & 407.46 \\
\hline \hline
\end{tabular}


Hayes and Turner used the Chow-Lin (1971) method to interpolate GDP estimates based on Quarterly Industrial Production as an indicator variable. They used a linear model rather than one specified in logarithms. Our methodology is an improvement on the Chow-Lin method and our use of a richer set of indicator variables suggests that our data offer a more accurate depiction of the macroeconomic path of the economy. The reliance on a single volatile series, such as industrial production, to derive quarterly data for GDP explains why the Hayes-Turner Series is more volatile than our series. While we have no independent means of verification, our method could in principle produce a series very similar to theirs if that were the most appropriate interpretation of the inter-relationships in the combined set of data. The fact that it did not is a reason for preferring our more stable series to theirs. As can be seen from Figure 2 which presents the data in index number form, apart from the matter of volatility in the Hayes-Turner series there are important turning point differences in 1929, 1931 and 1937-8. In using a richer set of indicators we get a better description of turning points.

Our market price and factor cost series are scarcely distinguishable when represented in this way; this does obscure some movements which may be of interest. For example, measured relative to the fourth quarter of 1929, our estimate of GDP at factor cost shows a decline of 7.9 per cent by the third quarter of 1931, while the measure at market prices shows a decline of only 7.4 per cent. The Hayes-Turner measure shows a decline of 5.7 per cent and puts the trough of the depression in the first quarter of 1931 with output 6.4 per cent below the figure for the fourth quarter of 1931.5

Foreman-Peck et al. (2000) used The Economist monthly Business Activity index, discussed above, to interpolate GDP on a monthly basis over the period 192736. We use our data for this period to investigate differences with this series. The correlation of the monthly growth rates for the two indices is -0.57 , suggesting that our method yields a very different high frequency description of the economy compared to simple interpolation based on the aggregate index. While we cannot compare these two indicators with an objective truth, we do note that the methods we

\footnotetext{
${ }^{5}$ It should be noted that these differences arise not only because of the differences in interpolation methodology, but also because we used the annual balanced GDP estimates provided by Sefton and Weale (1995) while Hayes and Turner used Feinstein’s (1972) data.
} 
use offer a rich means of making use of the available data and would, if that were statistically justifiable, deliver the results presented by Foreman-Peck et al.

Figure 2: Indicators of Quarterly GDP at 1938 prices

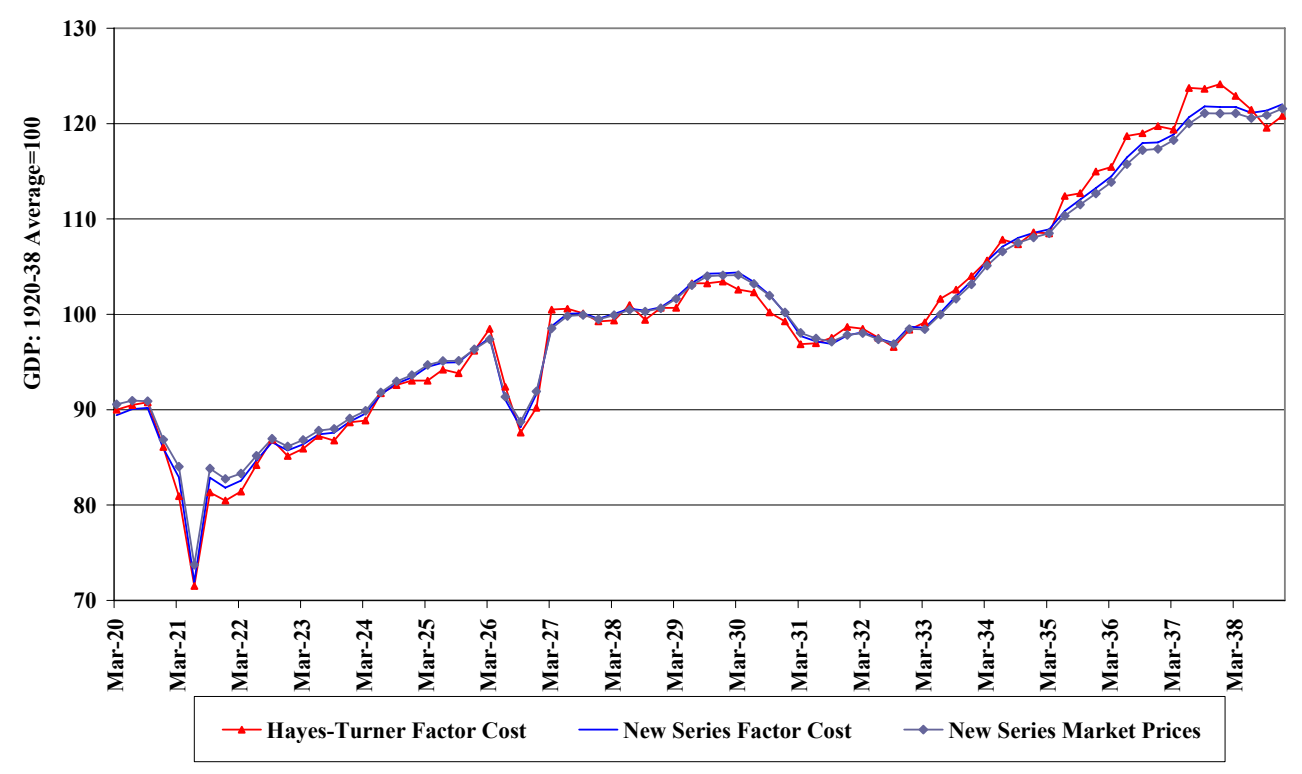


Table 2a: 1924-38 Quarterly GDP at Market Prices, £mn 1938 prices

\begin{tabular}{rrrrr}
\hline \hline & \multicolumn{1}{c}{ Q1 } & Q2 & \multicolumn{1}{c}{ Q3 } & Q4 \\
& & & & \\
$\mathbf{1 9 2 0}$ & 1020.15 & 1024.45 & 1024.01 & 978.38 \\
$\mathbf{1 9 2 1}$ & 946.71 & 830.68 & 944.34 & 932.27 \\
$\mathbf{1 9 2 2}$ & 938.33 & 959.48 & 979.58 & 970.61 \\
$\mathbf{1 9 2 3}$ & 978.11 & 989.13 & 991.18 & 1003.57 \\
$\mathbf{1 9 2 4}$ & 1012.59 & 1034.26 & 1047.39 & 1054.76 \\
$\mathbf{1 9 2 5}$ & 1066.69 & 1071.29 & 1071.72 & 1085.28 \\
$\mathbf{1 9 2 6}$ & 1096.85 & 1029.14 & 999.57 & 1035.45 \\
$\mathbf{1 9 2 7}$ & 1110.08 & 1124.56 & 1125.78 & 1120.59 \\
$\mathbf{1 9 2 8}$ & 1125.57 & 1131.76 & 1129.98 & 1133.70 \\
$\mathbf{1 9 2 9}$ & 1144.97 & 1160.84 & 1171.64 & 1172.54 \\
$\mathbf{1 9 3 0}$ & 1172.84 & 1162.69 & 1148.57 & 1128.90 \\
$\mathbf{1 9 3 1}$ & 1104.66 & 1098.08 & 1094.14 & 1102.13 \\
$\mathbf{1 9 3 2}$ & 1104.15 & 1096.95 & 1091.59 & 1109.32 \\
$\mathbf{1 9 3 3}$ & 1108.93 & 1126.27 & 1144.91 & 1161.89 \\
$\mathbf{1 9 3 4}$ & 1184.09 & 1200.58 & 1210.96 & 1217.38 \\
$\mathbf{1 9 3 5}$ & 1222.31 & 1243.04 & 1256.36 & 1269.28 \\
$\mathbf{1 9 3 6}$ & 1282.58 & 1303.87 & 1320.54 & 1322.01 \\
$\mathbf{1 9 3 7}$ & 1332.20 & 1351.75 & 1364.20 & 1363.86 \\
$\mathbf{1 9 3 8}$ & 1364.06 & 1358.50 & 1361.86 & 1369.58 \\
\hline \hline
\end{tabular}

Table 2b: 1924-38 Quarterly GDP at Factor Cost, £mn 1938 prices

\begin{tabular}{rrrrr}
\hline & \multicolumn{1}{c}{ Q1 } & Q2 & \multicolumn{1}{c}{ Q3 } & \multicolumn{1}{c}{ Q4 } \\
& & & & \\
$\mathbf{1 9 2 0}$ & 895.06 & 901.22 & 902.66 & 860.06 \\
$\mathbf{1 9 2 1}$ & 829.93 & 719.83 & 829.37 & 818.88 \\
$\mathbf{1 9 2 2}$ & 826.20 & 847.18 & 866.73 & 857.91 \\
$\mathbf{1 9 2 3}$ & 864.46 & 874.81 & 876.56 & 888.16 \\
$\mathbf{1 9 2 4}$ & 896.58 & 916.62 & 928.22 & 934.58 \\
$\mathbf{1 9 2 5}$ & 945.86 & 950.13 & 950.70 & 964.32 \\
$\mathbf{1 9 2 6}$ & 976.22 & 910.97 & 882.66 & 917.16 \\
$\mathbf{1 9 2 7}$ & 988.27 & 1001.38 & 1001.95 & 996.40 \\
$\mathbf{1 9 2 8}$ & 1001.07 & 1006.76 & 1004.87 & 1008.29 \\
$\mathbf{1 9 2 9}$ & 1018.82 & 1033.70 & 1043.53 & 1043.96 \\
$\mathbf{1 9 3 0}$ & 1044.69 & 1034.81 & 1021.27 & 1002.20 \\
$\mathbf{1 9 3 1}$ & 978.21 & 972.48 & 969.67 & 978.65 \\
$\mathbf{1 9 3 2}$ & 982.01 & 975.63 & 970.61 & 987.76 \\
$\mathbf{1 9 3 3}$ & 986.57 & 1002.68 & 1020.05 & 1035.71 \\
$\mathbf{1 9 3 4}$ & 1056.74 & 1071.84 & 1081.05 & 1086.37 \\
$\mathbf{1 9 3 5}$ & 1090.01 & 1109.30 & 1121.49 & 1133.21 \\
$\mathbf{1 9 3 6}$ & 1145.56 & 1165.42 & 1180.82 & 1181.20 \\
$\mathbf{1 9 3 7}$ & 1189.72 & 1207.68 & 1219.24 & 1218.36 \\
$\mathbf{1 9 3 8}$ & 1218.36 & 1212.39 & 1214.89 & 1221.35 \\
\hline \hline
\end{tabular}




\subsection{Monthly Industrial Production 1920-1938}

As noted earlier the UK has a quarterly industrial production index but we currently do not have a monthly index. We have used a mixed two stage estimation procedure to estimate monthly GDP; a by-product of this exercise is that we have also produced a monthly industrial production index. Given the limited set of indicators for the period 1920-23 it is likely that the GDP estimates for that period are of lower reliability than for the period 1924 onwards. However, the set of indicators for the period before 1924 (coal consumption, iron and steel consumption, cotton consumption, merchandise carried on railways and exports) are likely to be better indicators for industrial production than for GDP. Hence, the series for monthly industrial production, shown in Table 3, provides very useful information on the highfrequency movements of the economy during the major depression of 1920-1 (this is discussed below)

Table 3: 1920-1938 Monthly Industrial Production Series Average 1920-1938 $=100$

\begin{tabular}{ccccccccccccc}
\hline \hline & Jan & Feb & Mar & Apr & May & Jun & Jul & Aug & Sep & Oct & Nov & Dec \\
& & & & & & & & & & & \\
$\mathbf{1 9 2 0}$ & 117.1 & 117.1 & 114.8 & 115.0 & 118.2 & 118.8 & 121.2 & 124.8 & 115.1 & 111.3 & 96.0 & 99.6 \\
$\mathbf{1 9 2 1}$ & 84.9 & 95.0 & 78.8 & 73.6 & 39.9 & 55.0 & 86.8 & 98.0 & 86.0 & 87.7 & 82.4 & 82.6 \\
$\mathbf{1 9 2 2}$ & 80.7 & 84.3 & 84.8 & 88.1 & 92.8 & 89.9 & 100.8 & 97.6 & 99.5 & 91.0 & 94.2 & 88.6 \\
$\mathbf{1 9 2 3}$ & 95.7 & 94.7 & 95.5 & 99.2 & 97.3 & 104.4 & 93.5 & 100.9 & 94.4 & 104.1 & 94.9 & 101.9 \\
$\mathbf{1 9 2 4}$ & 91.6 & 100.2 & 94.1 & 103.2 & 99.1 & 104.6 & 101.2 & 105.2 & 100.5 & 102.4 & 99.6 & 101.9 \\
$\mathbf{1 9 2 5}$ & 98.9 & 102.0 & 96.9 & 103.4 & 96.5 & 101.0 & 93.9 & 96.6 & 92.3 & 97.6 & 95.7 & 98.5 \\
$\mathbf{1 9 2 6}$ & 98.4 & 100.1 & 96.3 & 97.7 & 63.8 & 61.2 & 60.3 & 58.8 & 61.5 & 58.5 & 69.6 & 76.5 \\
$\mathbf{1 9 2 7}$ & 105.7 & 97.7 & 118.5 & 105.6 & 118.8 & 109.5 & 113.6 & 109.1 & 108.3 & 107.1 & 103.8 & 105.0 \\
$\mathbf{1 9 2 8}$ & 100.7 & 106.4 & 99.9 & 110.7 & 100.7 & 107.6 & 96.2 & 105.1 & 96.6 & 105.4 & 97.2 & 107.4 \\
$\mathbf{1 9 2 9}$ & 99.9 & 109.1 & 103.9 & 115.8 & 108.4 & 118.8 & 111.0 & 118.8 & 110.2 & 115.6 & 108.4 & 113.0 \\
$\mathbf{1 9 3 0}$ & 106.4 & 111.3 & 101.2 & 107.7 & 98.5 & 103.7 & 93.9 & 98.8 & 90.1 & 93.4 & 88.8 & 88.6 \\
$\mathbf{1 9 3 1}$ & 81.3 & 84.3 & 81.1 & 82.2 & 82.6 & 81.9 & 83.9 & 84.4 & 84.5 & 86.7 & 88.6 & 89.4 \\
$\mathbf{1 9 3 2}$ & 87.6 & 89.1 & 87.9 & 86.7 & 84.2 & 84.8 & 82.7 & 81.7 & 79.3 & 82.3 & 82.3 & 91.1 \\
$\mathbf{1 9 3 3}$ & 84.0 & 86.6 & 85.1 & 90.7 & 88.8 & 94.4 & 91.1 & 94.0 & 91.7 & 95.0 & 93.3 & 97.6 \\
$\mathbf{1 9 3 4}$ & 97.1 & 101.9 & 98.8 & 107.5 & 100.5 & 107.9 & 98.8 & 106.8 & 98.3 & 105.3 & 98.3 & 106.3 \\
$\mathbf{1 9 3 5}$ & 96.6 & 106.0 & 98.4 & 113.3 & 104.5 & 116.2 & 106.0 & 115.4 & 106.5 & 116.4 & 108.5 & 118.1 \\
$\mathbf{1 9 3 6}$ & 107.9 & 118.8 & 110.4 & 123.1 & 115.0 & 126.0 & 116.7 & 126.8 & 114.6 & 123.7 & 112.6 & 121.8 \\
$\mathbf{1 9 3 7}$ & 109.6 & 124.5 & 111.9 & 131.9 & 119.7 & 136.5 & 122.0 & 134.0 & 123.1 & 130.5 & 121.8 & 123.8 \\
$\mathbf{1 9 3 8}$ & 119.5 & 122.2 & 113.3 & 115.6 & 107.7 & 110.7 & 102.1 & 107.2 & 100.6 & 108.8 & 102.2 & 107.9 \\
\hline \hline
\end{tabular}




\section{Historical Applications of the New Data}

In this section we illustrate three uses of the new data: first, we apply the high frequency information to evaluate the nature of the 1920-1 depression; second, we address the question of how the British economy came out of the Great Depression in the 1930s, in particular, is there evidence of expectation effects arising from the policies pursued in 1931-2; finally, we compare the high-frequency time-profile of depression and recovery in the Great Depression of the 1930s with more recent postwar recessions.

\subsection{The Nature of the 1920-1 Depression}

The high frequency data that we have derived has helped us gain a more complete picture of the severity of this depression. It is widely accepted that this is one of the most severe depressions affecting the UK economy since the $19^{\text {th }}$ century. During the peak-trough period of August 1920 and May 1921 GDP collapsed by close to 25 per cent and industrial production suffered a catastrophic collapse.

Earlier we noted that the new data show that the turning points of the 1920-1 cycle differ from the NBER dating of the British cycle. We also use more formal methods for dating the "classical business cycle" turning points by employing the nonparametric business cycle dating algorithm proposed by Harding and Pagan (2002); the results from this exercise agree with our visual inspection of the turning points as being August 1920 for the peak, and May 1921 for the trough. However, what is striking about the business cycle events between August 1920 and May 1921 is the break in the amplitude of the cyclical adjustments between April and August 1921. It is clear that what we are observing is a "cycle within a cycle” phenomenon. The economy weakens from mid-1920 and follows this path until March 1921. However, during April and May both industrial production and GDP display an accelerated path of decline only to rise rapidly again by July-August 1921. The explanation of this is that a coal strike began on $31^{\text {st }}$ March with coal rationing introduced on $3^{\text {rd }}$ April. The strike ended on $28^{\text {th }}$ June 1921, explaining the sharp recovery in July. The impact of the coal strike of 1921, in terms of man-days lost per 
striker and man-days lost per strike, suggests that the strike of 1921 had effects on output similar to those of the General Strike of 1926.

The previous literature on the 1920-1 depression has built an explanation in terms of a number of supply-side and demand side shocks. On the demand side, the policy announcements, from the end of 1919, of returning Britain to the gold standard at the pre-war par value resulted in a number of contractionary interest rate rises; this also acted on the real exchange rate resulting in significant appreciation (Solomou and Vartis, 2005). On the supply-side, the literature has stressed the hours of work reduction of 1919-20 and their impact on creating a wage gap as productivity failed to adjust (Broadberry, 1986). Although such factors may be acting on the economy, the new data suggests that the amplitude of the depression cannot be explained fully by these factors and the coal strike offers a further obvious explanation. However, once the strike was over the economy continued to weaken until the end of 1921.

\subsection{Economic Recovery in the 1930s}

Temin (1989) draws on Sargent (1983) to emphasise the importance of expectation changes as part of an underlying policy regime change to help economies out of the Great Depression. Temin argues that although Britain devalued in September 1931 the continuation of the policy framework of balanced budgets and restrictive monetary policy prevented an effective recovery in Britain during the 1930s. This contrasts with the experience of the USA -when Roosevelt succeeded President Hoover in March 1933 and announced the devaluation of the dollar, this was perceived as a powerful policy regime change that ended the depression in the USA. Similarly, Temin argues that Hitler's policy announcements in early 1933 represented a change big enough to shift expectations and end the depression in Germany. Temin is aware that to evaluate how policy regime change ended the Great Depression we need good quality high frequency data and provided some high frequency analysis of the recovery profiles in the USA and Germany. However, he did not provide the high-frequency data needed to analyse the British case. The new monthly GDP data allow us to evaluate the consistency of some of the ideas of the policy regime literature. 
Figure 1 and Table 1 show that the devaluation in September 1931 was correlated with a significant recovery, suggesting that expectation effects may have had an impact, since it is unlikely that trade volumes responded immediately, but it is quite clear that the recovery came to an abrupt end with another downturn in early 1932, suggesting a limited policy regime change. Devaluation in September 1931 was followed by monetary easing with "cheap money" in April 1932 and the General tariff in February $1932^{6}$. However, neither of these policies seems to have generated immediate observable effects on the path of recovery with the economy continuing to slide between February and September 1932. Clearly, Temin's hypothesis of an absence of observable recovery in 1931-2 is consistent with the new high-frequency data. The policy moves in the British economy during 1931-2 did not generate immediate expectation effects that were powerful enough to end the depression. However, beginning in October $1932^{7}$ the economy moved along a path of persistent and strong recovery, suggesting that Britain was able to recover effectively during the 1930s.

Temin's evaluation of the UK experience draws on the rational expectations policy framework. However, the early rational expectations models are recognised to be based on strong and unrealistic assumptions. Bray and Savin (1986) and Evans and Honkapohja (2001) suggest that the learning path of expectations may be important. The early rational expectations models assumed perfect information on the part of economic agents together with the assumption of a unique model and knowledge of its parameters. This is of course unrealistic, and an adaptive learning approach is proposed, where agents have to take time to gather information and learn about parameters in the same way as an econometrician. This is a specific form of bounded rationality and the forecast rule of agents is adjusted over time with the emergence of new data. If adaptive learning is assumed, then expectations may converge to the fully 'rational expectations' equilibrium eventually, but may not jump to such an equilibrium immediately. The evidence from the British high frequency data may be consistent with the idea that it took time to learn that the equilibrium expectations had changed. No single event determined this but along a bumpy path between September

\footnotetext{
${ }^{6}$ The Import Duties Act was introduced by Neville Chamberlain in February 1932 and came into operation on 1 March 1932.

${ }^{7}$ The algorithm proposed by Harding and Pagan (2002) for dating the turning point suggests that the transition to recovery takes place in October 1932.
} 
1931 and October 1932 the economy made a transition to a path of sustained recovery.

Such hesitant recovery paths have been observed more widely in the experience of the early 1930s. Eichengreen and Sachs (1985) report that on average there was hesitation between devaluation in the early 1930s and monetary expansion ${ }^{8}$. What does the British experience tell us about the role of policy regime change and the end of the Great Depression more generally? Clearly the British Government found it difficult to generate a favourable expectation effect instantaneously with any single policy move - be it devaluation, tariffs or monetary expansion. However, there are a series of policy reactions that may have contributed to the persistent and strong recovery from October 1932. We contend that the picture of the UK can be generalised to other countries responding to the Great Depression with devaluation in 1931- an adaptive learning process may turn out to be a more general perspective for analysing policy effects on expectations ${ }^{9}$. However, to address this broader issue arising from the British case study would require researchers to build a high frequency cross-country data set of the profile of depression and recovery in the 1930s and is outside the scope of this paper.

\subsection{Depression Profiles}

In this section we use the new data to compare the time-profile of depressions of the 1920s and 1930s with the three complete recessions of the post-war years and also with the current recession. The figures for the post-war years are calculated from the monthly GDP figures produced regularly by the National Institute of Economic and Social Research. These are computed monthly, making use of key monthly data (industrial production and retail sales) which are not available for the 1930s, and are always aligned against the latest quarterly official GDP data. While revisions to the official quarterly data can affect all the monthly estimates, obviously the data for the most recent recession are the most subject to change. All figures relate to GDP at

\footnotetext{
${ }^{8}$ Eichengreen and Sachs (1985) report that the mean lag between devaluation and monetary expansion was around 2 years in the early 1930s.

${ }^{9}$ The German case can also be incorporated into this perspective. Temin argues that the German recovery was delayed until the policy regime change of 1933. The German high frequency data suggests that recovery is built over a longer phase between 1932 and 1933 (Ritschl, 2002).
} 
market prices but the volume indices for the post-war years are aligned to chainlinked quarterly figures while the volume figures for the 1930s are linked to balanced Laspeyres measures.

The timing of the depressions is shown in Table 3. The start of each depression is the month in which GDP reached a peak and the last month is the month in which GDP was below this peak for the last time. It should be noted that this timing is sensitive to the end points being defined by the peak month rather than by, say, the peak of a centred three-month rolling average. Using the latter definition we would find, for example, that the current depression began in March 2008; even our choice of April may seem arbitrary. Working to the two decimal places our interpolands make possible, output seems to have been very slightly lower in April than in February. But to one decimal place the output levels are the same and on these grounds we have placed the start in April. Similarly the date of emergence is sensitive to the definition; we have chosen the month after the last month in which output was depressed below the previous peak.

Table 3: The Timing of Recent Depressions

\begin{tabular}{|c|c|}
\hline First Month & Last Month \\
\hline July 1920 & April 1924 \\
\hline January 1930 & January 1934 \\
\hline June 1973 & August 1976 \\
\hline June 1979 & June 1983 \\
\hline March 1990 & March 1993 \\
\hline April 2008 & \\
\hline
\end{tabular}

In Table 3 and Figure 3, in order to suppress short-term noise we measure the change in GDP relative to the three-month average centred on the peak month and we show the data as three-month centred moving averages ${ }^{10}$ with the pre-War and postWar depressions on separate graphs. The sharp fall in output in April 1921 and the recovery in July 1921 as a result of the beginning and end of the coal strike makes a

\footnotetext{
${ }^{10}$ For clarification, we remind the reader that in the dating of turning points reported above we used the actual monthly data. The use of three-month centred moving averages is limited to the comparison of the depression profiles.
} 
three-month moving average a poor representation of underlying output. We therefore plot for March 1921 the average of the February, March and July monthly data and for July 1921 we show the average of the March, July and August data. We indicate the average level of output during the three months of the strike.

The graph shows that the contraction was very sharp ahead of the strike and that output continued to fall to a trough of $9.3 \%$ below the pre-depression level just under eighteen months from the start of the depression. A gradual but not uniform process of recovery was then set in train with output recovering to its previous peak after forty-five months.

Figure 3: The Profiles of Six UK Depressions.

Figure 3a) 1920s and 1930s

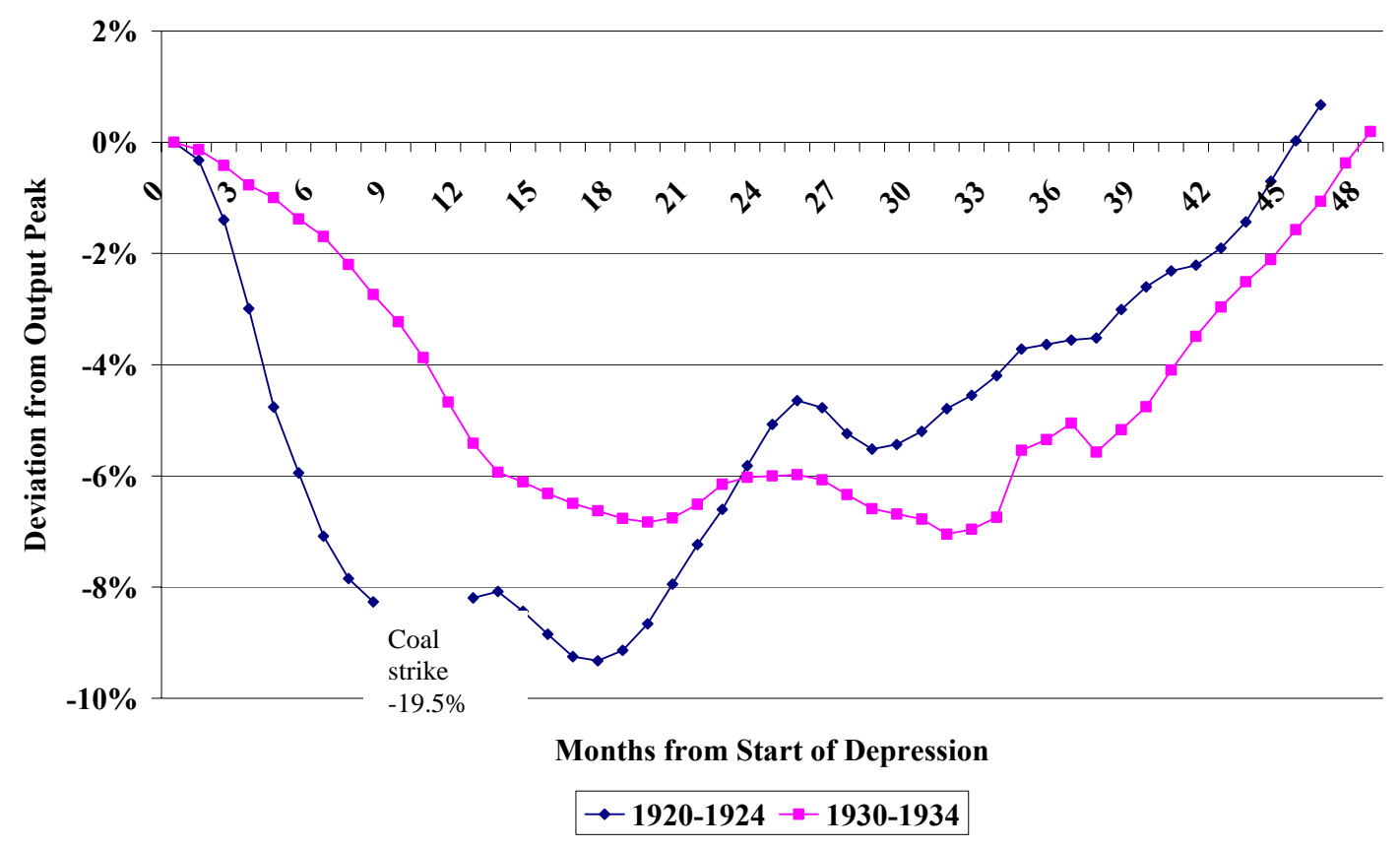


Figure 3b) Post-war depression profiles

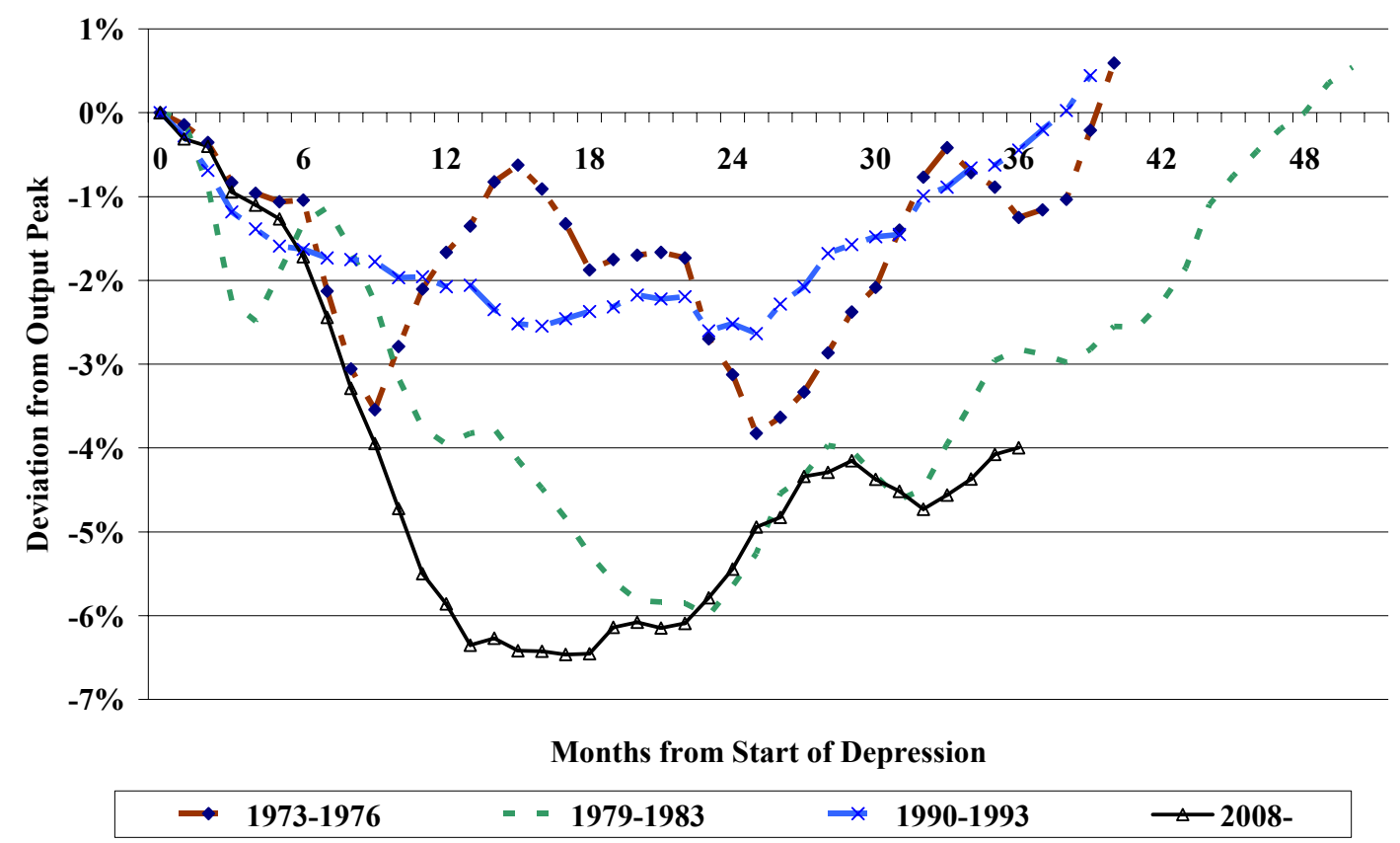

The depression of the 1930s was shallower than that of the 1920s even without the effects of the coal strike but it shows something of a double dip, with output falling about $6.8 \%$ after eighteen months and then recovering slightly before reaching a final trough of $7 \%$ below output at the start of the depression. This double dip extended the recession and it took forty-eight months for output to regain its predepression peak.

The post-war depressions are shown in Figure 3b. The depression which began in 1979 was only slightly shallower and similar in duration to that of the 1930s. The contraction was slower and, although the profile is erratic, there is nothing that could be described as a clear double dip. The period of falling output in the current recession was even sharper than that of the 1930s with a trough at seventeen months, but not as abrupt as that of the 1920s. However, so far a double dip has been avoided.

The other two depressions, of 1973-1976 and 1990-1993 were milder both in terms of depth and duration. Output moved erratically in the mid-1970s in part because of the effects of the three-day week at the start of 1974 and in that sense it has some similarities with the 1920s as a combination of a depression and the effects of 
industrial disruption. There was no similar disruption in the 1990s and this stands out as the mildest and shortest of the depressions we identify.

\section{Conclusions}

The strongest message from our analysis is that rather than use disparate indicators in an ad hoc manner to draw conclusions about the profiles of business cycles, it is preferable to use these variables to construct high-frequency estimates of GDP. There are two reasons for this. First of all, with no formal mechanism for aggregating disparate indicators it is not clear how judgement should be deployed in deciding how much importance to allocate to each; however if a formal mechanism for aggregation is used and it results in an indicator not directly related to GDP, the outcome can be only confusion. Secondly, if the indicator is not directly related to GDP it is not clear how to relate the monthly signals it provides to that offered in standard GDP data. Tools exist to interpolate GDP and we have shown here that, drawing on contemporaneously collected monthly data, they can be used to produce monthly estimates of GDP and Industrial production for the UK for the period 19201938. The interpolation methods have also been used to derive monthly series for industrial production.

The high frequency GDP data provided here have been shown to offer interesting insights into the British inter-war economy; we envisage that the data set will be of use to economists and economic historians addressing a number of questions that are best dealt with using high-frequency data. The need for improved historical data has been highlighted by the global financial crisis of 2008 which has resulted in renewed interest in the homologies between the current events and the Great Depression. This has resulted in the need for high frequency data covering both periods. To date the literature has been forced to use series for industrial production because they are available for both periods on a high frequency basis (Eichengreen and O’Rourke, 2009). However, in light of significant de-industrialisation over the post-war period, such comparisons can be very misleading when making macroeconomic comparisons. The monthly GDP series provided here allow for more relevant macroeconomic comparisons. 


\section{APPENDIX: The Data and Empirical Results}

The annual GDP data used (from 1920-1938) are the balanced constant price series at market values and taken from Sefton and Weale (1995, Table A.3, pp.188-189) ${ }^{11}$. The exercise, to ensure that the monthly GDP estimates over a calendar year sum to these annual data, is one of interpolation or, more precisely, distribution and has been considered, amongst others, by Chow and Lin (1971), Harvey and Pierse (1984) and Mitchell et al. (2005).

The Economist newspaper contains 14 index numbers from 1924m1-1938m12 pertaining to economic activity: employment, coal consumption, electricity consumption, railways, commercial motors in use, postal receipts, building activity, iron and steel for home consumption, raw cotton delivered to mills, imports: raw materials, exports of British manufactures, shipping movements, bank clearings (metropolitan) and banking clearings (town). For the period 1920m1-1923m12 a more limited set of indicators are available, comprising coal consumption, iron and steel consumption, cotton consumption, merchandise carried on railways and exports only. Seasonally adjusted data are used. Sims (1974) and Wallis (1974) examine the effects of seasonal adjustment on model estimation.

Plotting the 14 series from The Economist in Figure A1 we see the clear effect of both the 1921 coal strike and the General Strike in 1926. The 1921 coal strike led coal production to collapse from April to June 1921. Coal production also abruptly ceased in May-June 1926 and did not recover until the following year when the strike in the mines ended. The General Strike also had a similar effect on Iron and Steel for Home Consumption, with the whole economy clearly affected to some extent also. It is also of note that the data for Electricity were not available each month until 1927. Prior to this they are available at the quarterly frequency only. These missing observations are handled, as indicated, by the Kalman filter. What are effectively viewed as outliers, due to the coal strike in 1921 and the General Strike in 1926, are also tackled by setting the affected observations to missing values and letting the Kalman filter and smoother fill in the observations instead. Specifically, we set coal production to a

\footnotetext{
${ }^{11}$ It should be stressed that very similar results are obtained using Feinstein’s GDP data.
} 
missing value in 1921m4, when there was no coal production at all, and from 1926m5-1926m11. Coal production stopped for longer in the General Strike of 1926 than in 1921 (it stopped from May to July 1926). To mitigate the effect of the 1926 strike on our parameter estimates, and ensure estimates converge, we effectively 'dummy out' the biggest effect of the 1926 strike on coal production by also setting to missing values the three months following the cessation of coal production. We also set the $1926 \mathrm{~m} 5$ value to a missing value for several other affected indicator variables, although clearly judgement is deployed when deciding whether any downward movements in the other series is because of the strike or other factors. But the effect of the strike(s), to some extent, will still show up in our interpolated GDP and IP estimates since we force them to be consistent with both the annual GDP and quarterly IP data, which were affected by the strike(s). We have sought not to 'dummy out' the effects of the strikes on GDP and IP, but have used our judgement so that the model's parameters are not unduly influenced by these two strikes. This helps ensure that the model provides a good fit over the sample period as a whole. We note that similar results for the post 1927 period are in fact obtained if we do not correct for these outliers and commence estimation of model (1) in 1928. 
Figure A1: The Economist's monthly data
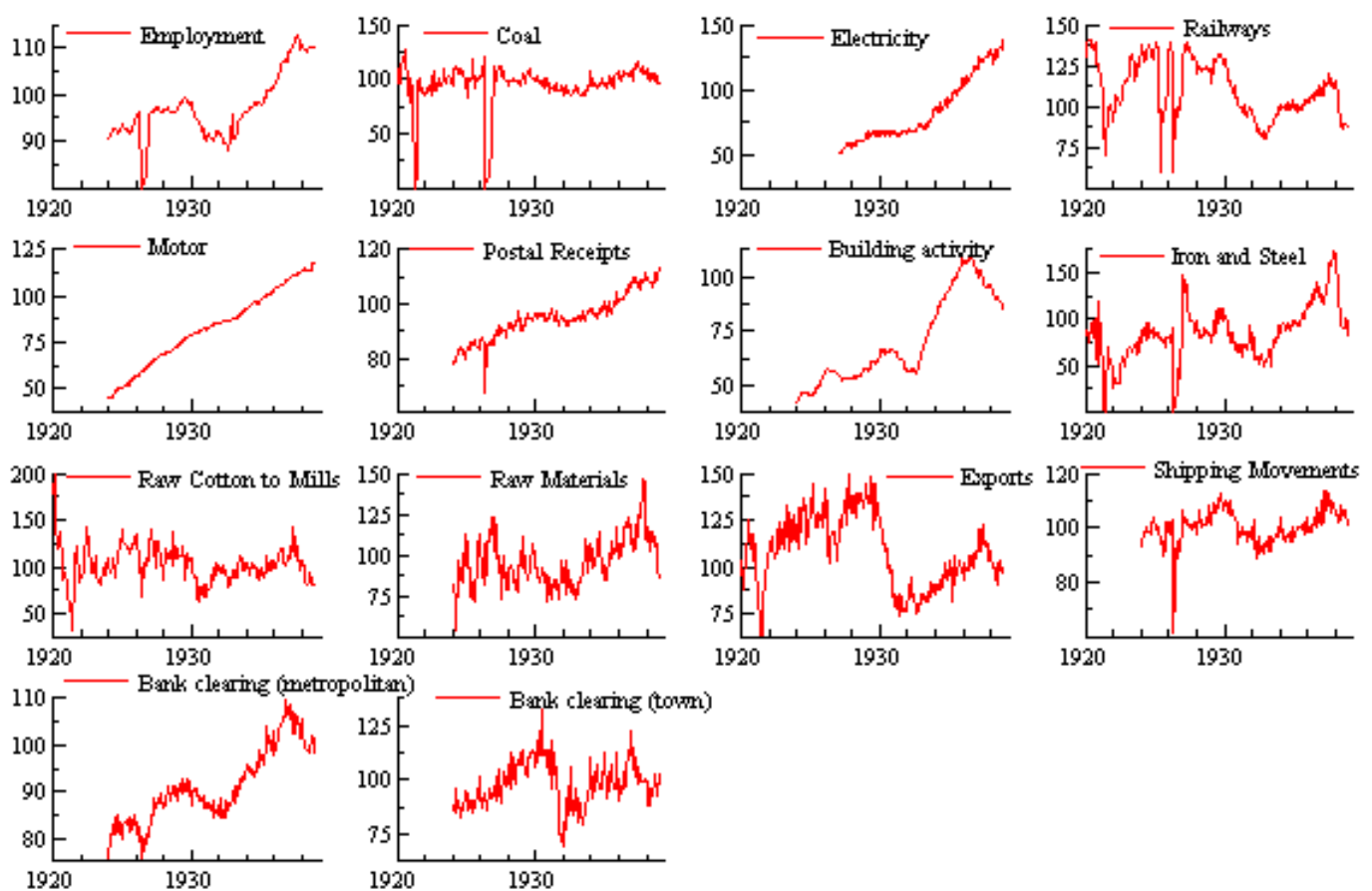

Assuming $\mathrm{AR}(1)$ processes ( $p=1$ and $\left.p_{i}=1\right)$ for the lag polynomials in model (1), the unknown parameters were then estimated by maximum likelihood exploiting the Kalman filter. The maximised value of the log-likelihood function, for the model explaining $\mathbf{y}_{t, m}=\left(\mathbf{y}_{1 t, m}^{\prime}, y_{2 t, m}, y_{3 t, m}\right)^{\prime}$, was 4546.689. The parameter estimates, and their asymptotic $t$-values, are presented in Table A1. The estimated factor loadings are all positive and are mostly significantly different from zero (at a 99\% level). This suggests that $\mu_{t, m}$ explains a statistically significant amount of the variation in the majority of The Economist's 14 series, as well as, importantly, monthly GDP itself. The sign of the estimated factor loadings is consistent with the view that all of The Economist's series are coincident indicators of economic activity. The $t$-values on the factor loadings are largest for employment, electricity consumption, raw cotton delivered to mills and GDP. This indicates that these four series are most sensitive to the "business cycle".

Inspection of the AR coefficients in Table A1 reveals that the common factor $\mu_{t, m}$ follows an autoregressive process with a positive coefficient, with the 
coefficients that determine the idiosyncratic components exhibiting some heterogeneity across the different indicators. We could not accept, via a Likelihood Ratio test, the restriction that the idiosyncratic components shared a common AR coefficient. The majority of the parameters are statistically significant and the model shows good overall fit.

Table A2 presents some model diagnostics based on the Kalman filter innovations from model (1). It shows that the model appears to be reasonably well specified, with most of the equations (for the different series) delivering innovations free from serial correlation. But there is some evidence of non-normality. The rejection of normality is explained by excess kurtosis (fat tails) which could not be eliminated by setting selected outlying observations to missing values. But the evidence for non-normality does weaken appreciably if estimation is confined to the 1924-1938 sub-period and thereby excludes the sharp recession of 1921. Importantly, irrespective of estimation window, the equation for GDP appears to be reasonably well specified. 
Table A1: Parameter estimates and their asymptotic t-values

\begin{tabular}{lrrrr}
\hline & \multicolumn{3}{l}{ Factor } & \multicolumn{2}{l}{ Autoregressive } \\
\hline & Coadings & & \\
\hline Employment & 0.03 & 16.19 & 0.00 & 0.02 \\
\hline Coal Consumption & 0.02 & 7.70 & 0.78 & 3.67 \\
\hline Electricity Consumption & 0.22 & 17.54 & -0.10 & -0.91 \\
\hline Railways & 0.01 & 2.16 & -0.50 & -6.89 \\
\hline Motor & 0.03 & 6.28 & -0.31 & -4.74 \\
\hline Postal Receipts & 0.00 & -0.29 & -0.22 & -3.02 \\
\hline Building activity & 0.00 & 1.26 & -0.40 & -5.77 \\
\hline Iron and Steel for Home consumption & 0.00 & 1.82 & 0.28 & 3.91 \\
\hline Raw Cotton delivered to Mills & 0.88 & 13.21 & -0.62 & -11.45 \\
\hline Imports: Raw Materials & 0.06 & 8.06 & -0.27 & -4.25 \\
\hline Exports British & 0.01 & 0.86 & -0.36 & -5.13 \\
\hline Shipping Movements & 0.02 & 4.15 & -0.36 & -5.80 \\
\hline Banking clearings & 0.03 & 7.49 & -0.44 & -6.48 \\
\hline Banking town & 0.01 & 3.16 & -0.52 & -7.84 \\
\hline Monthly Industrial Production: $y_{2 t, m}$ & 0.01 & 0.99 & -0.38 & -5.52 \\
\hline Monthly GDP: $y_{3 t, m}$ & 0.07 & 19.78 & -0.95 & -41.06 \\
\hline$\phi$ (AR coefficient for the “business cycle”) & - & - & 0.19 & 2.77 \\
\hline
\end{tabular}

Table A2: Diagnostic tests. The Box-Ljung test for no residual serial correlation with a maximum of 8 lags and the Bowman-Shenton test for normality

\begin{tabular}{lcc}
\hline & $\begin{array}{c}\text { Box- } \\
\text { Ljung }\end{array}$ & $\begin{array}{c}\text { Bowman- } \\
\text { Shenton }\end{array}$ \\
\hline Employment & 4.6 & 135.0 \\
\hline Coal Consumption & 11.7 & 65.0 \\
\hline Electricity Consumption & 9.3 & 0.3 \\
\hline Railways & 3.4 & 497.6 \\
\hline Motor & 5.8 & 15.9 \\
\hline Postal Receipts & 6.1 & 0.5 \\
\hline Building activity & 16.9 & 0.6 \\
\hline Iron and Steel for Home consumption & 115.0 & 106.7 \\
\hline Raw Cotton delivered to Mills & 4.4 & 2.3 \\
\hline Imports: Raw Materials & 4.4 & 24.5 \\
\hline Exports British & 19.0 & 7.7 \\
\hline Shipping Movements & 8.6 & 80.9 \\
\hline Banking clearings & 14.1 & 2.9 \\
\hline Banking town & 8.6 & 6.5 \\
\hline Monthly Industrial Production: $y_{2 t, m}$ & 31.5 & 103.5 \\
\hline Monthly GDP: $y_{3 t, m}$ & 3.1 & 7.2 \\
\hline & & \\
\hline 99\% critical value & 17.54 & 7.38 \\
\hline
\end{tabular}




\section{References}

Bray, M.M. and N.E. Savin. (1986), "Rational Expectations Equilibria, Learning and Model Specification”, Econometrica, Vol 54. pp. 1129-1160.

Broadberry, S.N. (1986) “Aggregate Supply in Interwar”, The Economic Journal, Vol. 96, 382, pp. 467-481.

Burns, A. F., and W. C. Mitchell (1946), Measuring Business Cycles. National Bureau of Economic Research, New York.

Capie, F. and Collins, M. (1983), The Inter-War British Economy; A Statistical Abstract, Manchester University Press.

Chow, G.C. and A Lin (1971), "Best Linear Unbiased Interpolation, Distribution, and Extrapolation of Time Series by Related Series”, Review of Economics and Statistics, Vol. 53, pp. 372-375.

Dow, C. (1998), Major Recessions: Britain and the World, 1920-1995, Oxford.

Eichengreen, B. \& J. Sachs (1985), "Exchange Rates and Economic Recovery in the 1930s”, Journal of Economic History, 45, pp. 925-46.

Eichengreen, B. \& K. O’Rourke (2009), “A Tale of Two Depressions.” http://www.voxeu.org/index.php?q=node/3421

Feinstein, C.H. (1972), National Income, Expenditure and Output of the United Kingdom: 1855-1972, Cambridge University Press.

Foreman-Peck J., Hughes-Hallett, A. and Ma, Y. (2000), “A monthly econometric model of the transmission of the Great Depression between the principal industrial economies”, Economic Modelling, 17, pp. 515-44.

Harding, D. and A. Pagan (2002), "Dissecting the cycle: a methodological investigation”, Journal of Monetary Economics, Vol. 49(2), pp. 365-381.

Harvey, A.C. and R.G Pierse (1984), "Estimating Missing Observations in Economic Time Series”, Journal of the American Statistical Association, Vol. 79, pp. 125-131.

Hayes, P. and Turner, P. (2007), "Estimates of Quarterly GDP for the Interwar UK Economy”, Applied Economics Letters, 14, pp. 569-572.

Mitchell, J, R. Smith, M. Weale, S. Wright and E. Salazar (2005), “An Indicator of Monthly GDP and an Early Estimate of Quarterly GDP Growth”, Economic Journal. Vol. 115, pp. 108-129.

Proietti, T. and F. Moauro (2006), "Dynamic factor analysis with non-linear temporal aggregation constraints”, Journal of the Royal Statistical Society: Series C, Vol. 55, pp. 281-300. 
Rhodes, E.C. (1937), “The Construction of an Index of Business Activity”, Journal of the Royal Statistical Society, Vol. 100. pp. 18-39.

Ritschl, A. (2002), Deutschlands Krise und Konjunktur.Binnenkonjunktur, Auslandsverschuldung und Reparationsproblem zwischen Dawes-Plan und Transfersperre 1924-1934,Berlin: Akademie-Verlag.

Sargent, Thomas (1983), "The Ends of Four Big Inflations," in Robert Hall (Ed.), Inflation: Causes and Effects, University of Chicago Press.

Sefton, J. and M.R. Weale (1995), Reconciliation of National Income and Expenditure: Balanced Estimates of National Income for the United Kingdom 19201990, Cambridge: Cambridge University Press.

Sims, C.A. (1974), "Seasonality in regression," Journal of the American. Statistical Association, 69, 618-626.

Solomou, S.N. and Weale, M.R. (1993), "Balanced Estimates of National Accounts when Measurement Errors are Autocorrelated: The UK 1920-38", Journal of the Royal Statistical Society, Series A, 156, Part 1.

Solomou, S.N. And Weale, M.R. 1996: 'UK National Income 1920-38: The Implications of Balanced Estimates', Economic History Review, XLIX, 1, pp. 101-15.

Solomou, S.N and Vartis, D. (2005): 'Effective Exchange Rates in Britain 1920-1930', Journal of Economic History, 65, 3, pp. 850-59.

Stock, J.H. and M.W. Watson (1991), “A Probability Model of the Coincident Economic Indicators". In Leading Economic Indicators: New Approaches and Forecasting Records (eds. Lahiri, K. and G., Moore), Cambridge: Cambridge University Press.

Stock, J.H., M.W. Watson (2002), "Macroeconomic forecasting using diffusion indexes”, Journal of Business and Economic Statistics, Vol. 20 pp.147 - 162

Stone, J. (1947), "On the interdependence of blocks of transactions”, Journal of the Royal Statistical Society Supplement. Vol. 9. pp. 1-32.

Temin, P. (1989), Lessons From The Great Depression, MIT Press.

Wallis, K.F. (1974), “Seasonal adjustment and relations between variables”, Journal of the American Statistical Association, 69, 18-31. 